\section{Peak shift on the tonal-frequency continuum: The effects of extinction and punishment*}

\author{
J. E. GERRY \\ Dalhousie University, Halifax, N.S., Canada
}

In an effort to extend the generality of the peak shift phenomenon to the tonal-frequency dimension, two pigeons were given extended intradimensional discrimination training on the tonal-frequency dimension. Both Ss displayed peak shifts early in discrimination training and loss or reduction of peak shift after more extended training. Introduction of response-contingent shock after each response to the $S-$ appeared sufficient to either yield marked recovery of peak shifts or increase the magnitude of existent peak shift. These data complement similar results obtained on other stimulus dimensions such as color and line orientation.

The phenomenon of generalization gradient peak shift has been demonstrated along a variety of stimulus dimensions following intradimensional discrimination training. These dimensions include color (see, e.g., Guttman, 1959, 1965; Hanson, 1959; Honig, Thomas, \& Guttman, 1959), line orientation (Bloomfield, 1967), and tonal intensity (Pierrel \& Sherman, 1960, 1962). Guttman (1965), however, suggested that peak shift may be specific to the color dimension, since Jenkins \& Harrison (1960) failed to report peak shifts on the tonal-frequency dimension. In this regard, Bloomfield (1967) noted that peak shifts generally follow only intradimensional discrimination training procedures, whereas the Jenkins \& Harrison (1960) training procedure was interdimensional.

Guttman's suspicions regarding peak shift find some support in the data of Jenkins \& Harrison (1962), where a slight peak shift on the tonal-frequency dimension was reported in only one of two pigeons tested. These two Ss first received interdimensional discrimination training and were only later shifted to an intradimensional discrimination. The lack of strong peak shifts in this study may well have resulted from this extensive prior interdimensional training and its gradient-sharpening effects (cf. Honig, 1969).

The present study was an attempt to demonstrate peak shift on the tonal-frequency continuum by following single stimulus training immediately with intradimensional discrimination training, i.e., omitting the interspersed interdimensional

*Preparation of this manuscript was aided by National Research Council of Canada Grant APT 102 to Werner K. Honig. Special thanks are due Drs. Warren M. Steinman, W. K. Honig, and N. J. Mackintosh. Reprints may be obtained from the author, Department of Psychology, Dalhousie University, Halifax, Nova Scotia, Canada. discrimination training of Jenkins \& Harrison (1962). The effects of, first, extinction and, later, punishment at the $\mathrm{S}$ - stimulus value on peak shift were investigated, since both of these contingencies are sufficient to yield peak shifts on the color continuum (cf. Hanson, 1959; Terrace, 1968).

The plan of the experiment was first to train a discrimination between one tonal-frequency value correlated with a variable interval 4-min (VI 4-min) reinforcement schedule and a second tonal-frequency correlated with extinction. Terrace (1966) has demonstrated the gradual loss of peak shift on the color dimension following extended intradimensional discrimination training between a stimulus correlated with VI 1-min reinforcement and a second stimulus correlated with extinction. Thus, in the present experiment, the loss of peak shift after extended training would provide an opportunity for observing any effects of punishment at $\mathrm{S}-$ on the location of the gradient peak, if the punishment contingency was introduced after extended training had removed the initial extinction-induced peak shifts.

$$
\text { SUBJECTS }
$$

The Ss were two naive white Carneaux pigeons, maintained at approximately $70 \%$ of ad lib weight throughout the experiment.

$$
\text { APPARATUS }
$$

A Lehigh Valley operant conditioning chamber for pigeons and associated solid-state programming and recording equipment was employed as the apparatus. The right response key of the chamber was illuminated with white light, and tones of varying frequency were presented through a speaker to the lower right of the illuminated key. The tones were generated by a Hewlett-Packard Model 200AB audio oscillator, set at an intensity of $50 \mathrm{~dB}$. The key illumination was the only illumination in the chamber, excepting the magazine light, which was operational during reinforcement. Reinforcements, consisting of $3 \mathrm{sec}$ of access to mixed grain, were delivered through an opening below the response key.

\section{PROCEDURE}

Preceding training, the appropriate shock level for punishing $S$ s was determined after the method of Hoffman, Fleshler, \& Jensen (1963). Both Ss were fitted with a 0.156-in.-diam bead chain which was wrapped twice around the base of each wing, from which the feathers had been removed. Shock was delivered to the birds via a flexible connector fastened to the bands of chain (cf. Hoffman, 1960). In a single session, each of the Ss was placed in a Plexiglas chamber, and a series of brief shocks of increasing intensity was presented until a level was found which produced a marked, but not violent, startle reaction.

Following determination of shock levels, initial training progressed in the following series of operations: (1) adaptation to the apparatus, (2) training to establish a baseline rate of responding on a VI 4-min reinforcement schedule correlated with a $1.3-\mathrm{kHz}$ tone and a white field on the response key, and (3) introduction of 10-sec periods of extinction correlated with a $1.0-\mathrm{kHz}$ tone and a white field on the key. In this latter discrimination training phase, St periods were $110 \mathrm{sec}$ in length and S- periods were gradually lengthened from 10 to $30 \mathrm{sec}$ over the first 30 sessions of discrimination training. The sequence of $\mathrm{S}+$ and $\mathrm{S}-$ presentation was determined by a probability generator set at 0.5 . Both Ss were trained on this discrimination for 64 sessions, each session lasting about $3 \mathrm{~h}$. Forty reinforcements were given during each session, and a time-out of 10 sec followed each $S+$ and $\mathrm{S}-$ period.

Repeated generalization tests were given throughout discrimination training; seven tests were given to $S 1$ and six given to $S 2$. The first three tests were given randomly during early training, while the following three tests were given to both $\mathrm{Ss}$ on the same days, each testing session separated from the one before by two training sessions. S 2 was given response-contingent electric shock of $1.5 \mathrm{~mA}$ and $0.5 \mathrm{sec}$ duration for each response in $S-$ during the two discrimination training sessions prior to the second and third of these last three generalization testing sessions. S 1 received no shock during this period of testing and served as a control for any effects of repeated generalization testing. Following these six testing sessions, $\mathrm{S} 1$ was given two additional training sessions with 1.5-mA, 0.5-sec-duration shock 


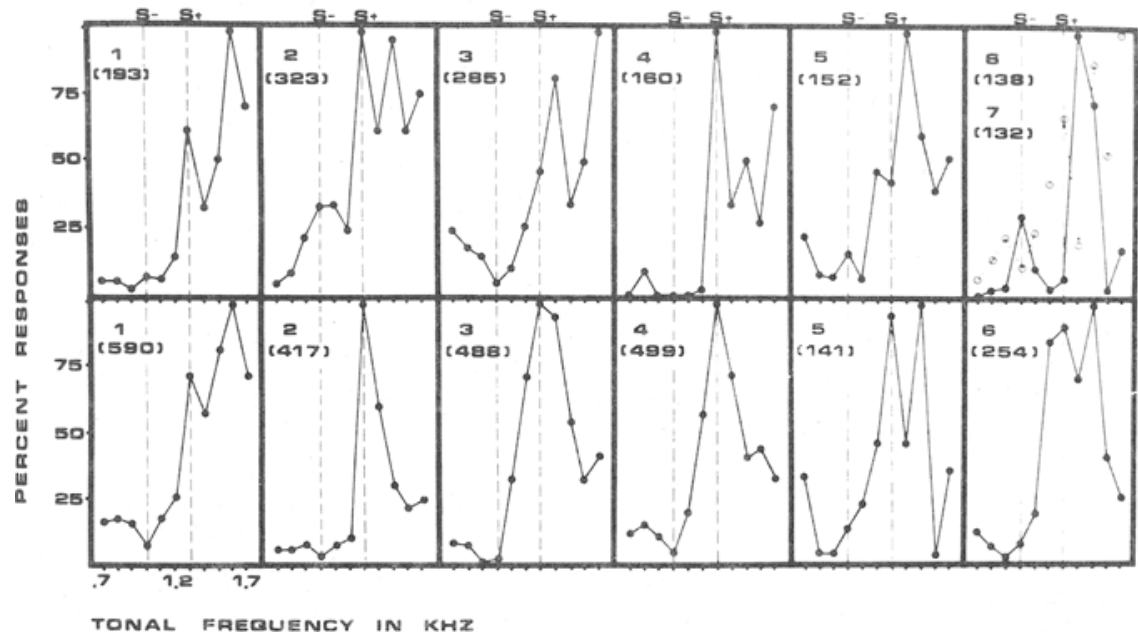

Fig. 1. Percent of responding to each peak stimulus emitted to the various other tonal generalization test stimuli by $S 1$ (upper six panels) and $S 2$ (lower six panels).

administered response-contingently in $\mathrm{S}-$. This $\mathrm{S}$ was then given a seventh generalization test. Thus, $\mathrm{S} 1$ served first as a control and later as an additional experimental $\mathbf{S}$.

Each generalization test was given in extinction and consisted of 10 randomized presentations of $0.7-, 0.8-$, $0.9-, 1.0-, 1.1-, 1.2-, 1.3-, 1.4-, 1.5-$, $1.6-$ and $1.7-\mathrm{kHz}$ tones. Test stimulus-on periods lasted $20 \mathrm{sec}$, with a 40 -sec intertrial interval. The response key was illuminated only during the actual stimulus-on periods, and no shocks were administered during any generalization testing session.

\section{RESULTS AND DISCUSSION}

Figure 1 displays the percentage generalization gradients of Ss 1 and 2 obtained by repeated generalization testing throughout discrimination training. These percentage gradients represent the number of responses emitted to each generalization test stimulus as a percentage of the number of responses emitted to the test stimulus occasioning the most responding, i.e., the peak stimulus of each generalization gradient. Percentage gradients for $S 1$ are shown in the six upper panels of Fig. 1, while the six lower panels contain the gradients of $S 2$. The number in the upper left of each panel designates the generalization test number for each $S$, while the number in parentheses below the test number indicates the number of responses emitted to the peak stimulus of each gradient. The latter value makes possible the reconversion of the percentages to raw numbers of responses emitted to the generalization test stimuli.
During Generalization Tests 1-4, both Ss initially displayed, and later lost, their peak shifts. S 1 showed a slight peak shift during Tests 5 and 6 , a result due, perhaps, to a sequence of long interreinforcement intervals in the VI 4-min reinforcement schedule during the training sessions immediately prior to these test sessions. The gradient shown in dashed lines and open circles is the seventh generalization test given $\mathrm{S} 1$. It was during the two training sessions just prior to this test that punishment was introduced in $\mathrm{S}-$ for this $\mathrm{S}$. The magnitude of peak shift in this seventh test was markedly greater than that of the Prepunishment Tests 4, 5, and 6.

S 2 displayed a récovery of peak shift following the introduction of punishment at $S-$ prior to Generalization Tests 5 and 6 . Also evident in this $S$ are shifts in the "trough" of the gradient during Postpunishment Tests 5 and 6 away from the $\mathrm{S}-$ in a direction also away from the $\mathrm{S}+$, i.e., either to 0.8 or $0.9 \mathrm{kHz}$. Such trough or "negative peak shifts" were first reported by Guttman (1965).

In summary, extinction at an $\mathrm{S}-$ on the tonal-frequency continuum generated peak shifts analogous to those observed on the color dimension. The disappearance of these peak shifts during extended training was similar to that described by Terrace (1966) for the color dimension, and the sufficiency of punishment to the production or enhancement of peak shift is in agreement with Terrace's (1968) demonstration of punishment-induced peak shifts on the color dimension.
The present data thus remove the shadow of doubt cast on the generality of peak shift to the tonal-frequency dimension by Guttman (1965) and the data of Jenkins \& Harrison (1962).

\section{REFERENCES}

BLOOMFIELD, T. M. A peak shift on a line-tilt continuum. Journal of the Experimental Analysis of Behavior, 1967, 10,361-366.

GUTTMAN, N. Generalization gradients around stimuli associated with different reinforcement schedules. Journal of the Experimental Analysis of Behavior, 1959 , 58, 335-340.

GUTTMAN, N. Effects of discrimination formation on generalization measured from a positive-rate baseline. In D. I. Mostofsky (Ed.), Stimulus generalization. Stanford, Calif: Stanford University Press, 1965. Pp. 255-267.

HANSON, H. N. Effects of discrimination training on stimulus generalization. Journal of Experimental Psychology, $1959,58,321-334$.

HOFFMAN, H. S. A flexible connector for delivering shock to pigeons. Journal of the Experimental Analysis of Behavior, $1960,3,330$.

HOFFMAN, H. S., FLESHLER, M., \& JENSEN, P. Stimulus aspects of aversive controls: The retention of conditioned suppression. Journal of the Experimental Analysis of Behavior, 1963,6,575-583.

HONIG. W. K. Attentional factors governing the slope of the generalization gradient. In R. M. Gilbert and N. S. Sutherland (Eds.), Animal discrimination learning. London: Academic Press, 1969. Pp. 35-62.

HONIG, W. K., THOMAS, D. R., \& GUTTMAN, N. Differential effects of continuous extinction and discrimination training on the generalization gradient. Journal of Experimental Psychology, $1959,58,145-152$.

JENKINS, H. M., \& HARRISON, R. H. Effect of discrimination training on auditory generalization. Journal of Experimental Psychology, 1960, 59, 246-253.

JENKINS, H. M., \& HARRISON, R. H. Generalization gradients of inhibition following auditory discrimination learning. Journal of the Experimental Analysis of Behavior, 1962, 5, 435-441.

PIERREL, R. \& SHERMAN, J. G. Generalization of auditory intensity following discrimination training. Journal of the Experimental Analysis of Behavior, $1960,3,313-322$.

PIERREL, R., \& SHERMAN, J. G. Generalization and discrimination as a function of the SD.S $\Delta$ intensity difference. Journal of the Experimental Analysis of Behavior, 1962, 5, 67-71.

TERRACE, H. S. Behavioral contrast and the peak shift: Effects of extended discrimination training. Journal of the Experimental Analysis of Behavior, 1966, 9, 613-617.

TERRACE, H. S. Discrimination learning, the peak shift, and behavioral contrast. Journal of the Experimental Analysis of Behavior, 1968, 11, 727-741. 